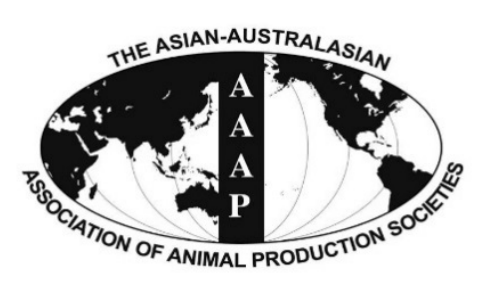

Open Access

Asian Australas. J. Anim. Sci.

Vol. 29, No. 6 : $768-774$ June 2016

http://dx.doi.org/10.5713/ajas.15.0907

www.ajas.info

pISSN 1011-2367 elSSN 1976-5517

\title{
Relationship between Body Weight of Primiparous Sows during Late Gestation and Subsequent Reproductive Efficiency over Six Parities
}

\author{
Jin Soo Kim, Xiaojian Yang, and Samuel Kofi Baidoo* \\ Southern Research and Outreach Center, University of Minnesota, Waseca, MN 56093, USA
}

\begin{abstract}
The present study investigated the impact of parity 1 gilt body weight during late gestation (d 109) on subsequent reproductive performance of sows and performance of suckling pigs. A total of 2,404 farrowing records over 6 parities were divided into six groups on the basis of body weight $(190,200,210,220,230$, and $240 \mathrm{~kg}$ ) at d 109 of gestation of 585 gilts. Significant effects (p< 0.05 ) of body weight on sow retention rate was noticed, with the $210 \mathrm{~kg}$ group having the lowest culling rate and highest total number of piglets born alive over the 6 parities. With increase of body weight, a linear increase $(p<0.05)$ in losses of body weight and backfat during the lactation period of parity 1 and a linear decrease $(p<0.05)$ in backfat loss for parities 4 and 6 were found. Compared with light sows, heavy sows had higher $(\mathrm{p}<0.05)$ litter weight at birth for parities 1 and 2 and at weaning in parity 1 . Sow weaning-to-estrus interval of sows was not influenced ( $p>0.05$ ) by body weight. In conclusion, maintaining optimal body weight during gestation would be beneficial to sows and suckling piglets. (Key Words: Gestation Body Weight, Parities, Reproductive Efficiency, Sow)
\end{abstract}

\section{INTRODUCTION}

The development of management practices that produce sows with a greater potential lifetime performance and decreasing attrition is crucial to the productivity of commercial production systems (Wilson and Ward, 2008). Modern sows are highly productive during lactation and therefore need high levels of nutrients intake during last phase of gestation. This is required to satisfy nutrient demand for maintenance for fetal development and reserve body fat which can be utilized during lactation-induced negative energy balance (Young et al., 2004). However, during the last phase of gestation and lactation sow feed intake is not sufficient to meet the nutrient requirements for maintenance, fetal growth and lactation, which leads to mobilization of protein and fat reserves (Aherne et al., 1999). Williams et al. (2005) suggested that gilts weigh at least $180 \mathrm{~kg}$ at first farrowing to minimize protein loss during lactation. However, sows with excess body weight at

\footnotetext{
* Corresponding Author: Samuel Kofi Baidoo. Tel: +1-507-8375626, Fax:+1-507-835-3622, E-mail: skbaidoo@umn.edu Submitted Nov. 11, 2015; Revised Jan. 12, 2016; Accepted Feb. 23, 2016
}

breeding or gestation are culled due to locomotion disorders before completing 3 parities (Williams et al., 2005; Amaral Filha et al., 2009). Therefore, sow body weight at the last phase of gestation should be maintained within an optimal range to ensure the best reproductive performance (Kummer, 2008).

It has been reported that maintaining sow body weight throughout reproductive cycle is more important than fixing this parameter at breeding or late gestation (Kummer, 2008). Body weight of sows reflects the total fat content of the sow and can be used to check whether the feeding strategies are optimal for reproductive performance (Mullan and Williams, 1990). Also, gestation body weight and backfat thickness during different parities can be used as an indicator for health status and productivity levels of sows (Barnett et al., 2001). However, information regarding sow body weight during last phase of gestation at different parities and its impact on reproductive performance and sow longevity is limited. Therefore, the objective of the present study was to investigate associations between primiparous sow body weight during last phase of gestation (d 109) and the reproductive efficiency of sows during subsequent parities. 


\section{MATERIAL AND METHODS}

\section{Animals and management}

The database used in the present study was obtained from the Swine Research Unit of Southern Research and Outreach Center at the University of Minnesota, Waseca, Minnesota, USA. A total of 2,404 farrowing records during the period 2009 to 2012 from 585 Large White $\times$ Danish Landrace sows were collected. Lactating sows were divided into six groups on the basis of body weight (190, 200, 210, 220,230 , and $240 \mathrm{~kg}$ ) at $109 \mathrm{~d}$ of gestation in parity 1 (Table 1). The actual mean and standard deviation of body weight at d 109 of gestation in parity 1 for the six groups were $191 \pm 9,205 \pm 3,215 \pm 3,224 \pm 3,246 \pm 5 \mathrm{~kg}$, respectively. All the sows were fed a common corn-soybean meal based diet as per NRC (1998) requirements for gestation and lactation. During gestation, sows were housed in individual stalls for the first 35 days after breeding and then moved to large group pens (60 sows/pen) equipped with electronic feeders if the pregnancy check showed a positive result. Sows were moved to farrowing rooms on d 109 of gestation and housed individually in fully slatted farrowing crates after sows were washed and their body weight and backfat recorded. Each crate had a single feeder, and water was always available through a nipple drinker for sows and piglets. The farrowing room temperature was maintained at approximately $18^{\circ} \mathrm{C}$ to $20^{\circ} \mathrm{C}$. Rooms were mechanically ventilated. A heat lamp and mat (Osborne Industries Inc., Osborne, KS, USA) were provided for newborn piglets in each crate. After weaning, sows were returned to their gestation housing systems.

\section{Data collection and measurements}

Sows were weighed and introduced to their lactation diets, beginning from d 109 of gestation and were provided with $2.5 \mathrm{~kg}$ of feed until parturition. Cross-fostering was encouraged within the first 2 days of farrowing. After farrowing, feed was gradually increased through $\mathrm{d} 5$, and then sows were allowed ad libitum intake until weaning (d 18). Sows were fed twice daily at 0730 and $1430 \mathrm{~h}$ such that they were allowed ad libitum access to feed and water. The quantity of feed provided per sow was recorded daily from d 1 to 18 . Feed refusals were weighed and recorded at weaning. No creep feed was provided to suckling piglets. Sow body weight and ultrasonic backfat depth at the P2 position were measured (Lean-Meater, Renco Corp., Minneapolis, MN, USA) on d 109 of gestation and at weaning (d 18). Loss of body weight and backfat thickness during lactation was calculated by subtracting the values at weaning from values at d 109 of gestation. Litters were weighed on $\mathrm{d} 1$ and 18 . Other sow and litter information was also collected, such as parity of the sow and litter size at birth and weaning. Total piglets born alive over 6 parities were calculated with consideration of sow retention rate by summing the number piglets produced for all gilts that were initially artificially inseminated (Patterson et al., 2010). If a sow did not produce a litter in any parity, total born alive of the sow was recorded as 0 for that parity.

\section{Statistical analysis}

The Cochran-Armitage test is commonly used to determine the existence of trends in binomial proportions of a dose response relationship. For each time point (parity), we used the Cochran-Armitage test to examine the association of sow cumulative culling rate with body weight at d 109 of gestation of parity 1 . Sows were culled at discrete points in time, i.e. parities. Because there were many ties, a logit model for discrete-time data was used (Allison, 2010). In the logistic regression model, year, month, and parity were included as categorical variables, and body weight at d 109 of gestation was treated as either a categorical or continuous variable. Culling related data were analyzed by the maximum likelihood method using the LOGISTIC procedure of SAS.

Sow reproductive performance and litter related data were analyzed by mixed model using the GLIMMIX procedure of SAS 9.2 (SAS Inst. Inc., Cary, NC, USA). Categorized body weight at d 109 of gestation of parity 1 , parity $(1,2,3,4,5$, and 6$)$, farrowing year, farrowing month, and the interaction between parity and categorized body weight at d 109 of gestation were specified as fixed effects. Sow was included as a random effect to account for repeated measurements on individual sows. In the mixed model, the response variables were sow related

Table 1. Distribution of sow on the basis of body weight $(\mathrm{kg})$ at $109 \mathrm{~d}$ of gestation during different parities and sow retention rate ${ }^{1}(\%)$

\begin{tabular}{lccccccc}
\hline \multirow{2}{*}{ Parity } & \multicolumn{7}{c}{ Weight $(\mathrm{kg})$ of sows at d 109 of gestation in parity 1} \\
\cline { 2 - 5 } & 190 & 200 & 210 & 220 & 230 & p-value \\
\hline 1 & 118 & 112 & 109 & 92 & 69 & 85 & 240 \\
2 & $105(88.98)$ & $97(86.60)$ & $100(91.74)$ & $74(80.43)$ & $53(76.81)$ & $71(83.53)$ & 0.32 \\
3 & $91(77.12)$ & $84(75.00)$ & $96(88.07)$ & $64(69.56)$ & $45(65.22)$ & $60(70.59)$ & 0.05 \\
4 & $82(69.49)$ & $72(64.29)$ & $82(75.23)$ & $52(56.52)$ & $36(52.17)$ & $51(60.00)$ & 0.02 \\
5 & $68(57.63)$ & $59(52.68)$ & $68(62.39)$ & $39(42.39)$ & $29(42.03)$ & $39(45.88)$ & 0.01 \\
6 & $48(40.68)$ & $40(35.71)$ & $43(39.45)$ & $26(28.26)$ & $21(30.43)$ & $24(28.24)$ & 0.03 \\
\hline
\end{tabular}

${ }^{1}$ Sow retention rate $(\%)$ in brackets. Sow culling rate $(\%)=100-$ retention rate. 
Table 2. Effects of body weight at $109 \mathrm{~d}$ of gestation on daily feed intake $(\mathrm{kg} / \mathrm{d})$ of lactating sows during different parities

\begin{tabular}{|c|c|c|c|c|c|c|c|c|c|}
\hline \multirow{2}{*}{ Parity } & \multicolumn{6}{|c|}{ Weight $(\mathrm{kg})$ of sows at d 109 of gestation in parity 1} & \multirow{2}{*}{ SEM } & \multicolumn{2}{|c|}{ p-values ${ }^{1}$} \\
\hline & 190 & 200 & 210 & 220 & 230 & 240 & & $\mathrm{~L}$ & Q \\
\hline 1 & 4.80 & 4.74 & 4.61 & 4.56 & 4.42 & 4.39 & 0.13 & 0.07 & 1.00 \\
\hline 2 & 6.07 & 6.46 & 6.26 & 6.40 & 6.32 & 6.45 & 0.17 & 0.36 & 0.62 \\
\hline 3 & 6.81 & 7.22 & 6.73 & 6.92 & 6.91 & 6.92 & 0.17 & 0.96 & 0.87 \\
\hline 4 & 7.04 & 6.87 & 6.72 & 7.21 & 6.49 & 6.95 & 0.19 & 0.58 & 0.64 \\
\hline 5 & 6.18 & 7.13 & 6.63 & 6.84 & 6.73 & 7.15 & 0.39 & 0.08 & 0.59 \\
\hline 6 & 5.97 & 6.02 & 7.46 & 6.48 & 7.21 & 7.26 & 0.39 & $<0.01$ & 0.42 \\
\hline
\end{tabular}

SEM, standard error of means.

${ }^{1}$ Linear (L) and quadratic (Q) effects of increasing parity 1 sow body weight at $109 \mathrm{~d}$ of gestation.

measurements (feed intake, body weight and backfat thickness at $\mathrm{d} 109$ of gestation and weaning, losses of body weight and backfat during lactation) or piglet related measurements (total born alive, litter size at weaning and litter weight). Orthogonal polynomial contrasts were used to evaluate linear and quadratic effects of body weight at d109 gestation of parity 1 on performance of sows and piglets for all 6 parities. Coefficients of the orthogonal polynomial contrasts were generated by the interactive matrix language procedure of SAS using actual group means of body weight of d 109 gestation of parity 1 . Least squares means and the associated standard errors were reported. For data presented in tables, pooled standard error of the mean was calculated with the mean squared error and the harmonic mean due to unequal replicates among groups (Renteria-Flores et al., 2008). Significance level was set at 0.05 and values between 0.05 and 0.1 were considered trends.

\section{RESULTS}

Relationships between body weight at $\mathrm{d} 109$ of gestation and culling rate, feed intake, body weight and backfat thickness during lactation

The retention rate for parity 3 sows was $88 \%$ to $65 \%$ and $40 \%$ to $28 \%$ parity 6 sows (Table 1 ). The probability of being culled increased $(\mathrm{p}<0.05)$ from parity 3 as body weight of sows at d 109 of gestation increased as revealed by the Cochran-Armitage test. Logistic regression analysis with body weight as a categorical variable showed that, compared with the heaviest group $(240 \mathrm{~kg})$, the odds of being culled were $31 \%(p=0.08)$ and $39 \%(p=0.02)$ lower for groups $1(190 \mathrm{~kg})$ and $3(200 \mathrm{~kg})$, respectively. Furthermore, logistic regression analysis with body weight as a continuous variable revealed that an increase of $1 \mathrm{~kg}$ body weight at day 109 of gestation in parity 1 led to an increase in sow culling odds by $0.6 \%(\mathrm{p}=0.09)$.

Increasing d 109 gestation body weight was associated with a linear change in daily feed intake of lactating sows in parities 1 (decrease; $p=0.07$ ), 5 (increase; $p<0.05$ ) and 6 (increase; $p=0.08$ ) (Table 2). Gestation body weight had no effects (linear or quadratic: $p>0.10$ ) on feed intake of second to fourth parity lactating sows.

Sow body weight increased linearly $(\mathrm{p}<0.05)$ for parities 1, 2, 3, and 4 (at d 109 of gestation) and 1, 2, and 3 (at weaning) with increase of sow d 109 gestation body weight in parity 1 . However, a linear increase $(p<0.05)$ in body weight loss from d 109 of gestation to weaning was only noticed in parity 1 (Figure 1). Backfat at d 109 of gestation and weaning increased linearly during parities 1

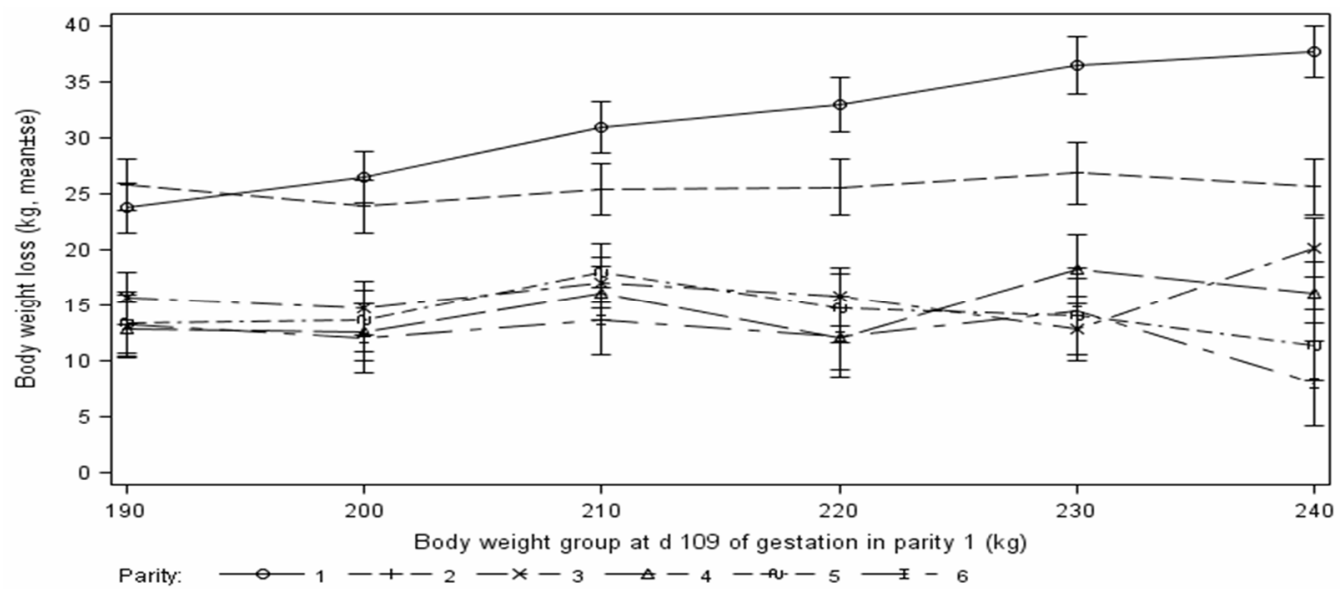

Figure 1. Effects of parity 1 sow weight at d 109 of gestation on sow body weight loss from d 109 of gestation to weaning over 6 parities. 


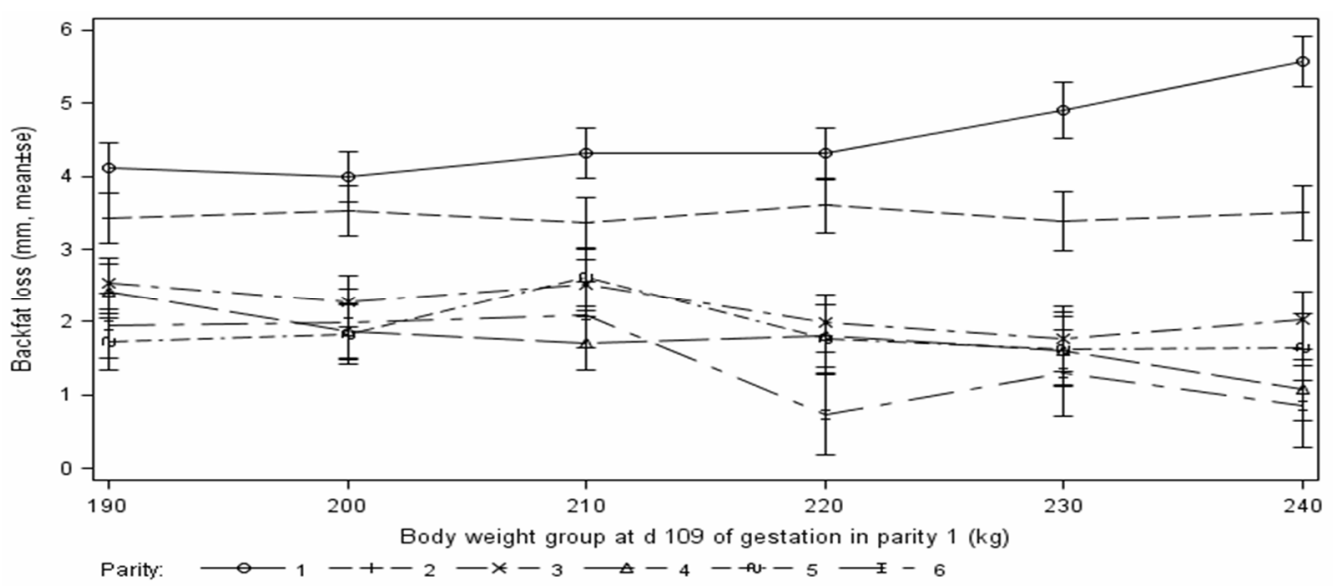

Figure 2. Effects of parity 1 sow weight at d 109 of gestation on sow backfat loss during lactation over 6 parities.

$(\mathrm{p}<0.05)$ and $2(\mathrm{p}<0.10)$, but reduced linearly $(\mathrm{p}<0.05$ or $\mathrm{p}<0.10)$ during parities 4 to 6 , with no difference $(\mathrm{p}>0.10)$ in parity 3 , when sow body weight increased. Backfat loss during lactation increased linearly $(\mathrm{p}<0.05)$ in parity 1 , but dropped linearly $(\mathrm{p}<0.05)$ during parities 4 and 6 with increase of sow body weight at $109 \mathrm{~d}$ of gestation (Figure 2).

\section{Relationships between body weight at d 109 of gestation and reproductive efficiency}

Total number of piglets born alive increased linearly in parities $1(\mathrm{p}<0.05)$ and $5(\mathrm{p}=0.07)$ when $\mathrm{d}-109$ gestation body weight of parity 1 increased (Table 3 ). Litter size at weaning increased linearly $(\mathrm{p}<0.05)$ for parities 1 and 5 but dropped linearly $(p<0.05)$ in parity 4 with increase of $d-109$ gestation body weight. Total pigs born alive adjusted for culling rate over 6 parities were 46.6, 43.9, 50.9, 42.4, 42.3, and 44.9 for body weight groups 1 to 6 (190 to $240 \mathrm{~kg}$ ), respectively, suggesting that $210 \mathrm{~kg}$ of body weight at d 109 of gestation in parity 1 had the highest total born alive.

Initial litter weight increased linearly $(p<0.05)$ with increase in sow gestation body weight during first, second and fifth parity (Table 4). Litter weight at weaning increased linearly $(p<0.05)$ during first parity but decreased linearly $(p<0.05)$ for parity 4 as $d-109$ gestation body weight increased (Table 4). Average of the weaning-toestrus interval was 6.8 days and the interval was not significantly influenced ( $p>0.05$ ) by $d-109$ gestation body weight.

\section{DISCUSSION}

The optimum sow body weight and body condition during gestation and lactations is essential to maximize productivity and ensure efficient utilization of feed. In modern swine industry, it is customary to evaluate sow body weight and backfat thickness during various phases of production cycle to adjust feeding levels to maintaining optimal body condition of sows to achieve adequate reproductive efficiency, litter performance and sow longevity (Maes et al., 2004; Theil et al., 2014). The optimum body weight during gestation will moderate lactation weight loss and provide the best conditions for

Table 3. Effects of parity 1 sow weight at d 109 of gestation on litter size over 6 parities

\begin{tabular}{|c|c|c|c|c|c|c|c|c|c|c|}
\hline \multirow{2}{*}{ Item } & \multicolumn{7}{|c|}{ Weight $(\mathrm{kg})$ of sows at d 109 of gestation in parity 1} & \multirow{2}{*}{ SEM } & \multicolumn{2}{|c|}{ p-values ${ }^{1}$} \\
\hline & Parity & 190 & 200 & 210 & 220 & 230 & 240 & & $\mathrm{~L}$ & Q \\
\hline \multirow[t]{6}{*}{ Numbers born alive } & 1 & 10.21 & 10.81 & 11.63 & 11.84 & 12.45 & 13.08 & 0.11 & $<0.01$ & 0.71 \\
\hline & 2 & 11.51 & 10.85 & 11.20 & 11.34 & 11.77 & 11.31 & 0.12 & 0.59 & 0.62 \\
\hline & 3 & 11.24 & 11.09 & 11.63 & 11.41 & 10.91 & 11.69 & 0.13 & 0.64 & 0.83 \\
\hline & 4 & 11.20 & 10.56 & 11.12 & 11.49 & 11.13 & 10.63 & 0.14 & 0.75 & 0.47 \\
\hline & 5 & 9.91 & 9.90 & 10.34 & 9.91 & 10.51 & 10.94 & 0.16 & 0.07 & 0.46 \\
\hline & 6 & 9.87 & 9.33 & 9.86 & 10.04 & 11.31 & 9.78 & 0.19 & 0.24 & 0.73 \\
\hline \multirow[t]{6}{*}{ Numbers weaned } & 1 & 9.56 & 9.63 & 9.85 & 9.82 & 10.20 & 10.10 & 0.10 & $<0.01$ & 0.91 \\
\hline & 2 & 10.00 & 9.97 & 9.88 & 9.99 & 10.08 & 10.32 & 0.11 & 0.26 & 0.28 \\
\hline & 3 & 10.09 & 10.17 & 10.08 & 10.04 & 9.99 & 10.16 & 0.12 & 0.91 & 0.80 \\
\hline & 4 & 10.18 & 9.65 & 9.72 & 9.91 & 9.53 & 9.39 & 0.14 & $<0.01$ & 0.93 \\
\hline & 5 & 8.55 & 9.50 & 9.58 & 9.25 & 9.61 & 10.00 & 0.16 & $<0.01$ & 0.39 \\
\hline & 6 & 9.15 & 8.71 & 9.39 & 8.67 & 9.73 & 9.64 & 0.19 & 0.51 & 0.85 \\
\hline
\end{tabular}

SEM, standard error of means.

${ }^{1}$ Linear (L) and quadratic (Q) effects of increasing parity 1 sow body weight at $109 \mathrm{~d}$ of gestation. 
Table 4. Effects of parity 1 sow weight at d 109 of gestation on litter weight $(\mathrm{kg})$ over 6 parities

\begin{tabular}{|c|c|c|c|c|c|c|c|c|c|c|}
\hline \multirow{2}{*}{ Item } & \multicolumn{7}{|c|}{ Weight $(\mathrm{kg})$ of sows at d 109 of gestation in parity 1} & \multirow{2}{*}{ SEM } & \multicolumn{2}{|c|}{ p-values ${ }^{1}$} \\
\hline & Parity & 190 & 200 & 210 & 220 & 230 & 240 & & $\mathrm{~L}$ & $\mathrm{Q}$ \\
\hline \multirow[t]{6}{*}{ Initial } & 1 & 14.32 & 15.42 & 16.54 & 17.09 & 17.68 & 19.28 & 0.39 & $<0.01$ & 0.82 \\
\hline & 2 & 17.76 & 17.06 & 18.32 & 18.59 & 18.71 & 18.57 & 0.52 & 0.03 & 0.82 \\
\hline & 3 & 17.77 & 17.58 & 18.85 & 17.98 & 17.08 & 18.47 & 0.53 & 0.75 & 0.95 \\
\hline & 4 & 17.30 & 16.73 & 17.82 & 17.96 & 17.32 & 16.65 & 0.59 & 0.75 & 0.18 \\
\hline & 5 & 15.52 & 15.15 & 16.37 & 15.20 & 15.91 & 18.11 & 0.77 & 0.01 & 0.05 \\
\hline & 6 & 16.24 & 14.72 & 15.56 & 15.91 & 16.78 & 15.47 & 0.81 & 0.75 & 0.80 \\
\hline \multirow[t]{6}{*}{ Final } & 1 & 58.24 & 59.78 & 60.89 & 60.38 & 63.15 & 64.42 & 1.18 & $<0.01$ & 0.68 \\
\hline & 2 & 69.60 & 70.87 & 70.43 & 70.09 & 70.58 & 73.29 & 1.46 & 0.19 & 0.46 \\
\hline & 3 & 70.36 & 70.64 & 70.00 & 67.74 & 67.85 & 69.06 & 1.49 & 0.26 & 0.66 \\
\hline & 4 & 66.98 & 65.44 & 65.53 & 66.36 & 61.09 & 61.10 & 2.05 & 0.04 & 0.86 \\
\hline & 5 & 57.21 & 61.53 & 63.34 & 60.61 & 62.46 & 60.49 & 2.81 & 0.31 & 0.09 \\
\hline & 6 & 59.97 & 55.62 & 59.87 & 55.17 & 62.42 & 59.08 & 3.21 & 0.63 & 0.43 \\
\hline
\end{tabular}

SEM, standard error of means.

${ }^{1}$ Linear (L) and quadratic (Q) effects of increasing parity 1 sow body weight at $109 \mathrm{~d}$ of gestation.

optimal milk production and litter performance (Kummer, 2008). In the present study, we investigated the relationships between sow body weight during the last stage of gestation (d 109) of parity 1 and reproductive performance of sows over 6 parities.

From parity 3 in the present study the probability of being culled increased as body weight of sows during d 109 of gestation increased, with $210 \mathrm{~kg}$ as the optimal weight. If we assume $65 \mathrm{~kg}$ of total gestational weight gain during the first parity, gilt body weight at breeding would be then 145 $\mathrm{kg}$. Kummer (2008) observed that first parity sows bred at greater than $180 \mathrm{~kg}$ were at greater risk of having reduced retention to third parity, largely as a result of increased culling due to locomotion problems. It was reported that sows with excess body weight at breeding or gestation were culled due to locomotion disorders before reaching 4 parity (Williams et al., 2005; Amaral Filha et al., 2009). However, during the last phase of gestation and lactation sow feed intake is not sufficient to meet the nutrient requirements for maintenance, fetal growth and lactation, which leads to mobilization of protein and fat reserves (Aherne et al., 1999). The excessive loss of body weight through mobilization of backfat and reserve protein during gestation was linked with reduced litter performance (Clowes et al., 2003) and reproductive efficiency of sows (De Rensis et al., 2005; Serenius et al., 2006). Therefore, sow body weight at the last phase of gestation should be maintained within an optimal range to ensure the best reproductive performance. Williams et al. (2005) recommended that gilts weight should be at least $180 \mathrm{~kg}$ at first farrowing to minimize protein loss during lactation. However, excess body weight at last phase of gestation leads to reproductive disorders such as farrowing difficulties, more stillborn piglets (Zaleski and Hacker, 1993), postpartum dysgalactia, and higher culling rate due to locomotion difficulties (Dourmad et al., 2001).
Adequate feed intake during lactation is necessary to maximize sow productivity and to maintain body reserve (Aherne et al., 1999; Estienne et al., 2003; Maes et al., 2004). Decreased feed intake during the lactation period results in excessive loss of body weight and difficulties to maintain milk production and growth of litter. In the present study, daily feed intake of lactating sows tended to decrease linearly with increase in gestation body weight during first parity. Our results are consistent with Estienne et al. (2003), who observed that during lactation heavy sows consumed less feed compared with thin and medium sows. O'Grady et al. (1985) showed that body conditions at farrowing influenced feed intake during gestation, with sows consuming 4.9, 4.7, and $4.5 \mathrm{~kg}$ per day for thin, fat, and very fat sows, respectively. It was shown that excessive feed intake during early gestation increases embryonic death in gilts (Jindal et al., 1996) and decreased feed intake during lactation (Dourmad, 1991; Weldon et al., 1994). In general, feed intake during lactation is influenced by numerous factors such as parity, environmental temperature and level of feeding during gestation, through the integration of neural, hormonal, and nutrient signals. Modern sows are highly productive during lactation and therefore need high levels of nutrient intake during last phase of gestation for body maintenance and growth and fetal development and reserve body fat which can be utilized during lactation negative energy balance (Young et al., 2004).

Increased in body weight of sows at d 109 of gestation resulted in an increase in lactation body weight loss of sow in our current study. This could be partly due to lower feed intake during lactation as indicated by linear increase in backfat loss with increase in gestation body weight of sows during first parity. In addition, the increased body and backfat loss with increase in gestation weight during first parity might be due partly to increase in litter size and 
weight. Goodband et al. (2013) observed that extra feed in late gestation increased sow weight gain and could influence pig survivability during lactation and increase pig birth weight in parity 1 farrowing sows. Increase-weightloss in primiparous sows need a longer recovery period from their negative energy balance during lactation than decrease-weight-loss in primiparous sows or multiparous sows. Body weight at d 109 of gestation and weaning were similar among the 6 groups for parities 5 and 6 as reported in this study. Several investigators have demonstrated that sows losing excessive amounts of body weight have extended weaning to estrous intervals and an increase in anoestrus. However, in the present study weaning to estrus interval was not significantly affected by sow body weight at d 109 of gestation.

The sow body condition can be judged by measurement of the backfat thickness during various stages of gestation and lactation (Charette et al., 1996). Maintaining optimal backfat thickness and body condition during gestation and lactation is crucial for subsequent reproductive performance (Tummaruk et al., 2007; Houde et al., 2010). Lactation backfat loss linearly increased with increase in sow body weight at $109 \mathrm{~d}$ of gestation during first parity as indicated in this study. However, during the fourth and sixth parity, backfat loss was reduced linearly with increase in body weight of parity 1 sows at $109 \mathrm{~d}$ of gestation. Increased lactation backfat loss during first parity might be due to lower lactation feed intake and increased litter size and litter weight. Maes et al. (2004) and Houde et al. (2010) observed that backfat thickness loss of gilts and sows mainly occurred due to negative energy balance during lactation. In addition, it was reported that backfat loss was proportional to number of live piglet weaned (Maes et al., 2004) and that sows with reduced backfat thickness weaned fewer piglets per litter (McKay, 1993). Variations in feed intake, feeding pattern and milk production between sows during lactation are likely responsible for variation in backfat thickness and losses of backfat at weaning (Kokestu et al., 1996; Maes et al., 2004).

The sow body weight is affected by two main factors, genetics and nutrition. However, the genetics factor may not be fully controlled, because modern day breeding are aimed to have less backfat thickness but more lean carcass as market demand. Therefore, the nutritional manipulation to adjust body weight of sows during gestation and lactations is a possible factor which sow producers can practice. Information obtained herein can be used as tool to adjust the optimal body weight during late gestation and lactation for obtaining best reproductive performance of sows during different parities. Moreover, this information can be used as tools to modify the feeding strategies for gestating and lactating sows.

\section{CONFLICT OF INTEREST}

We certify that there is no conflict of interest with any financial organization regarding the material discussed in the manuscript.

\section{REFERENCES}

Aherne, F., G. Foxcroft, and J. E. Pettigrew. 1999. Nutrition of the sow. In: Diseases of Swine. 8th edn (Eds. B. E. Straw, S. D'Allaire, W. L. Mengeling, and D. J. Taylor). Iowa State University Press, Ames, IA, USA. pp. 1029-1043

Allison, P. D. 2010. Survival Analysis Using SAS: A Practical Guide, Second Edition. SAS Institute, Cary, NC, USA.

Amaral Filha, W. S., M. L. Bernardi, I. Wentz, and F. P. Bortolozzo. 2009. Growth rate and age at boar exposure as factors influencing gilt puberty. Livest. Sci. 120:51-57.

Barnett, J. L., P. H. Hemsworth, G. M. Cronin, E. C. Jongman, and G. D. Hutson. 2001. A review of the welfare issues for sows and piglets in relation to housing. Aust. J. Agric. Res. 52:1-28.

Charette, R., M. Bigras-Poulin, and G. Martineau. 1996. Body condition evaluation in sows. Livest. Prod. Sci. 46:107-115.

Clowes, E. J., F. X. Aherne, A. L. Schaefer, G. R. Foxcroft, and V. E. Baracos. 2003. Parturition body size and body protein loss during lactation influence performance during lactation and ovarian function at weaning in first-parity sows. J. Anim. Sci. $81: 1517-1528$

De Rensis, F., M. Gherpelli, P. Superchi, and R. N. Kirkwood. 2005. Relationships between backfat depth and plasma leptin during lactation and sow reproductive performance after weaning. Anim. Reprod. Sci. 90:95-100.

Dourmad, J.-Y. 1991. Effect of feeding level in the gilt during pregnancy on voluntary feed intake during lactation and changes in body composition during gestation and lactation. Livest. Prod. Sci. 27:309-319.

Dourmad, J. Y., M. E'tienne, and J. Noblet. 2001. Measuring backfat depth in sows to optimize feeding strategy. INRA Prod. Anim. 14:41-50.

Estienne, M. J., A. F. Harper, D. M. Kozink, and J. W. Knight. 2003. Serum and milk concentrations of leptin in gilts fed a high- or low-energy diet during gestation. Anim. Reprod. Sci. 75:95-105.

Goodband, R. D., M. D. Tokach, M. A. D. Goncalves, J. C. Woodworth, S. S. Dritz, and M. DeRouchey. 2013. Nutritional enhancement during pregnancy and its effects on reproduction in swine. Anim. Front. 3:68-75.

Houde, A. A., S. Me'thot, B. D. Murphy, V. Bordignon, and M. F. Pali. 2010. Relationships between backfat thickness and reproductive efficiency of sows: A two-year trial involving two commercial herds fixing backfat thickness at breeding. Can. J. Anim. Sci. 90:429-436.

Jindal, R., J. R. Cosgrove, F. X. Aherne, and G. R. Foxcroft. 1996. Effect of nutrition on embryonal mortality in gilt: Association with progesterone. J. Anim. Sci. 74:620-624.

Koketsu, Y., G. Dial, J. Pettigrew, W. Marsh, and V. King. 1996. Characterization of feed intake patterns during lactation in commercial swine herds. J. Anim. Sci. 74:1202-1210.

Kummer, R. 2008. Growth and reproductive maturity of 
replacement gilts. 2008 Swine Breeding Management Workshop. Setting up the Herd, Edmonton, AB, Canada.

Maes, D. G. D., G. P. J. Janssens, P. Delputte, A. Lammertyn, and A. de Kruif. 2004. Backfat measurements in sows from three commercial pig herds: Relationship with reproductive efficiency and correlation with visual body condition scores. Livest. Prod. Sci. 91:57-67.

McKay, R. M. 1993. Pre-weaning losses of piglets as a result of index selection for reduced backfat thickness and increased growth rate. Can. J. Anim. Sci. 73:437-442.

Mullan, B. P. and I. H. Williams. 1990. The chemical composition of sows during their first lactation. Anim. Prod. 51:375-387.

NRC 1998. Nutrient Requirements of Swine, 10th edn. National Academy Press, Washington DC, USA

O'Grady, J. F., P. B. Lynch, and P. A. Kearney. 1985. Voluntary feed intake by lactating sows. Livest. Prod. Sci. 12:355-365.

Patterson, J. L., E. Beltranena, and G. R. Foxcroft. 2010. The effect of gilt age at first estrus and breeding on third estrus on sow body weight changes and long-term reproductive performance. J. Anim. Sci. 88:2500-2513.

Renteria-Flores, J. A., L. J. Johnston, G. C. Shurson, R. L. Moser, and S. K. Webel. 2008. Effect of soluble and insoluble dietary fiber on embryo survival and sow performance. J. Anim. Sci. 86:2576-2584.

Serenius, T., K. J. Stalder, T. J. Baas, J. W. Mabry, R. N. Goodwin, R. K. Johnson, O.W. Robinson, M. Tokach, and R. K. Miller. 2006. National Pork Producers' Council Maternal Line National Genetic Evaluation Program: A comparison of sow longevity and trait associations with sow longevity. J. Anim. Sci. 84:2590-2595.
Tummaruk, P., W. Tantasuparuk, M. Techakumphu, and A. Kunavongkrit. 2007. Age, body weight and backfat thickness at first observed estrus in crossbred Landrace Yorkshire gilts, seasonal variations and their influence on subsequent reproductive performance. Anim. Reprod. Sci. 99:167-181.

Theil, P. K., C. Lauridsen, and H. Quesnel. 2014. Neonatal piglet survival: impact of sow nutrition around parturition on fetal glycogen deposition and production and composition of colostrum and transient milk. Animal 25:1-10.

Weldon, W. C., A. J. Lewis, G. F. Louis, J. L. Kovar, and P. S. Miller. 1994. Postpartum hypophagia in primiparous sows II. Effects of feeding level during gestation and exogenous insulin on lactation feed intake, glucose tolerance, and epinephrinestimulated release of nonesterified fatty acids and glucose. J. Anim. Sci. 72:395-403

Williams, N., J. Patterson, and G. R. Foxcroft. 2005. Nonnegotiables in gilt development. In: Advances in Pork Production 16. Univ. Alberta, Edmonton, Alberta, Canada. pp. 1-16.

Wilson, M. E. and T. L. Ward. 2008. Lameness hurts sow reproduction. Zinpro Feet First Symp., Minneapolis, MN, USA. pp. 64-74.

Young, M. G., M. D. Tokach, F. X. Aherne, R. G. Main, S. S. Dritz, R. D. Goodband, and J. L. Nellssen. 2004. Comparison of three methods of feeding sows in gestation and the subsequent effects on lactation performance. J. Anim. Sci. 82:3058-3070.

Zaleski, H. M. and R. R. Hacker. 1993. Variables related to the progress of parturition and probability of stillbirth in swine. Can. Vet. J. 34:109-113. 